\title{
The importance of assessing positive and beneficial impacts of alien species
}

\author{
Giovanni Vimercati', Sabrina Kumschick ${ }^{2,3}$, \\ Anna F. Probert', Lara Volery', Sven Bacher' \\ I Department of Biology, Unit Ecology \& Evolution, University of Fribourg, Chemin du Musée 10, 1700 Fri- \\ bourg, Switzerland 2 Centre for Invasion Biology, Department of Botany and Zoology, Stellenbosch University, \\ Matieland 7602, South Africa 3 South African National Biodiversity Institute, Kirstenbosch Research Centre, \\ Cape Town, South Africa
}

Corresponding author: Giovanni Vimercati (gvimercati@outlook.com)

Academic editor: Q. J. Groom | Received 1 April 2020 | Accepted 2 September 2020 | Published 15 October 2020

Citation: Vimercati G, Kumschick S, Probert AF, Volery L, Bacher S (2020) The importance of assessing positive and beneficial impacts of alien species. In: Wilson JR, Bacher S, Daehler CC, Groom QJ, Kumschick S, Lockwood JL, Robinson TB, Zengeya TA, Richardson DM (Eds) Frameworks used in Invasion Science. NeoBiota 62: 525-545. https:// doi.org/10.3897/neobiota.62.52793

\begin{abstract}
Extensive literature is available on the diversity and magnitude of impacts that alien species cause on recipient systems. Alien species may decrease or increase attributes of ecosystems (e.g. total biomass or species diversity), thus causing negative and positive environmental impacts. Alien species may also negatively or positively impact attributes linked to local human communities (e.g. the number of people involved in a given activity). Ethical and societal values contribute to define these environmental and socio-economic impacts as deleterious or beneficial. Whilst most of the literature focuses on the deleterious effects of alien taxa, some recognise their beneficial impacts on ecosystems and human activities. Impact assessment frameworks show a similar tendency to evaluate mainly deleterious impacts: only relatively few, and not widely applied, frameworks incorporate the beneficial impacts of alien species. Here, we provide a summary of the frameworks assessing beneficial impacts and briefly discuss why they might have been less frequently cited and applied than frameworks assessing exclusively deleterious impacts. Then, we review arguments that invoke a greater consideration of positive and beneficial impacts caused by alien species across the invasion science literature. We collate and describe arguments from a set of 47 papers, grouping them in two categories (value-free and value-laden), which span from a theoretical, basic science perspective to an applied science perspective. We also provide example cases associated with each argument. We advocate that the development of transparent and evidence-based frameworks assessing positive and beneficial impacts might advance our scientific understanding of impact dynamics and better inform
\end{abstract}

Copyright Giovanni Vimercati et al. This is an open access article distributed under the terms of the Creative Commons Attribution License (CC BY 4.0), which permits unrestricted use, distribution, and reproduction in any medium, provided the original author and source are credited. 
management and prioritisation decisions. We also advise that this development should be achieved by recognising the underlying ethical and societal values of the frameworks and their intrinsic limitations. The evaluation of positive and beneficial impacts through impact assessment frameworks should not be seen as an attempt to outweigh or to discount deleterious impacts of alien taxa but rather as an opportunity to provide additional information for scientists, managers and policymakers.

\section{Keywords}

Biological invasions, environmental impacts, human well-being, impact assessment frameworks, nature conservation, prioritisation, socio-economic impacts

\section{Introduction}

The number of species which are introduced beyond their native ranges (i.e. alien species) continues to rise among geographic regions and taxonomic groups (Essl et al. 2011; Seebens et al. 2017). A vast literature is now available on the variety and magnitude of impacts (here defined as measurable changes as in Ricciardi et al. 2013) that alien species cause in native biodiversity and human well-being (Pimentel et al. 2001; Mazza et al. 2014; Shackleton et al. 2019a). Alien species may decrease and/or increase attributes of their recipient ecosystem (e.g. total biomass or species diversity), thus causing negative and positive environmental impacts. Alien species may also negatively and/or positively impact attributes linked to humans (e.g. the number or income of people involved in a given activity). Ethical and societal values, for instance, associated with nature conservation and human well-being, define whether these environmental and socio-economic impacts are perceived as deleterious or beneficial (Kumschick et al. 2012; Shackleton et al. 2019b). The majority of studies in the field of invasion science have focused on deleterious impacts only (Goodenough 2010; Guerin et al. 2018). The general focus on the deleterious effects of alien species has been motivated by the necessity and urgency to study the serious consequences that some have on native communities and human activities (Richardson et al. 2000; Pyšek et al. 2008; Guerin et al. 2018). The research focus on deleterious impacts has resulted in detailed descriptions of the mechanisms through which alien animals, plants and pathogens may damage recipient ecological and socio-economic systems (Vilà et al. 2010; Ricciardi et al. 2013; Blackburn et al. 2014; Vaz et al. 2017; Bacher et al. 2018). Such knowledge has been used to prioritise the most deleterious alien species and adopt management countermeasures (Oreska and Aldridge 2011; McGeoch et al. 2016; Roy et al. 2017). However, sustained attention on deleterious impacts could have led to an unwarranted disregard for their beneficial impacts, thus resulting in a simplified, if not misleading, understanding of impact dynamics (Goodenough 2010; Boltovskoy et al. 2018). As a result, there has been some disagreement over the use of terminology and the interpretation of data among invasion scientists (Boltovskoy et al. 2018). Guerin et al. (2018), for example, suggested that meta-analyses quantifying the impact of alien species might not be fully objective, as these studies are often characterised by selection 
bias toward highly deleterious taxa (but see also Kuebbing and Nuñez 2018, who argued that potential publication biases do not necessarily invalidate findings). Another potential consequence is the risk of implementing controversial management policies: management decisions based only on deleterious impacts ignore the fact that there might be conflicts of interest among stakeholders (Zengeya et al. 2017; Potgieter et al. 2019a; Kumschick et al. 2020a).

The general tendency to focus mainly on the deleterious impacts of alien taxa can also be observed in the impact assessment frameworks developed over the last decades. These frameworks adopt science-based approaches to estimate impact magnitude, describe mechanisms underlying impacts and facilitate comparisons across different taxonomic groups and geographic regions. However, only a subset of these impact assessment frameworks evaluate beneficial impacts. Of nine impact assessment frameworks developed in the last two decades, only three frameworks include strategies to incorporate beneficial impacts of alien species into the impact assessment process (Table 1). Frameworks focusing exclusively on deleterious impacts have been cited more often than those incorporating beneficial impacts, which may indicate that the latter are relatively less applied in the scientific community. Although we acknowledge that using the number of citations as a proxy for frequency of application might not always be appropriate, we found that this index reflects well with how often the different frameworks have been applied.

The conceptual framework proposed by Kumschick et al. (2012) uses a bidirectional ranking scale to estimate socio-economic and environmental impacts of alien taxa. In such a scheme, negative and positive socio-economic impacts mirror each other, with the former describing decreases in a measured variable that is relevant to humans (such as forestry and animal production) and the latter describing increases of the same variable. Environmental benefits, on the contrary, are evaluated by assessing the capacity of alien taxa to modify the ecosystem towards a hypothesised historical functional state. Despite the novel approach and insights provided, this framework is less frequently cited (Table 1), and applied than other schemes that exclusively assess negative impacts such as GISS (Generic Impact Scoring System, Nentwig et al. 2016) and EICAT (Environmental Impact Classification for Alien Taxa, Blackburn et al. 2014). This relatively low number of citations can be due to a variety of factors, including the high structural complexity of the framework, which requires to weigh impacts according to their importance for various stakeholders, or the successive development of other, more detailed, impact assessment frameworks such as EICAT. The framework proposed by Katsanevakis et al. (2014) describes multiple mechanisms by which marine alien species affect biodiversity (e.g. by habitat engineering) and ecosystem services (e.g. by ocean nourishment), both beneficially and deleteriously. Although the impact magnitude was not considered (i.e. local-, small-, and large-scale impacts were all treated equally) such a framework allowed the screening of a high number of marine species (87), finding most (67) cause both deleterious and beneficial impacts. Although the framework is highly cited within the scientific community (Table 1), most of the citations arise because of the large documentation on impact variation of alien species in the European seas. On the contrary, the same framework has been very rarely applied to assess deleterious and beneficial impacts of 
Table I. List of impact assessment frameworks which assess environmental and/or socio-economic impacts developed in the last 30 years. The list has been compiled following Roy et al. 2007, Bartz and Kowarik 2019, Srebaliene et al. 2019, Strubbe et al. 2019 and Vilà et al. 2019. The total number of citations per article corrected by year has been obtained from Google Scholar in June 2020.

\begin{tabular}{|c|c|c|c|c|c|c|}
\hline General name & $\begin{array}{l}\text { Target spatial } \\
\text { area }\end{array}$ & Target taxa & References & $\begin{array}{c}\text { Explicit } \\
\text { assessment } \\
\text { of beneficial } \\
\text { impacts }\end{array}$ & $\begin{array}{l}\text { Type of impact }(\mathrm{E}= \\
\text { Environmental, } \mathrm{SE} \\
=\text { Socio-Economic })\end{array}$ & $\begin{array}{c}\text { Number of } \\
\text { citations / year } \\
\text { (total number of } \\
\text { citations) }\end{array}$ \\
\hline $\begin{array}{c}\text { Invasive species } \\
\text { assessment protocol: } \\
\text { evaluating non-native } \\
\text { plants for their impact } \\
\text { on biodiversity }\end{array}$ & USA & Plants & $\begin{array}{l}\text { Morse et al. } \\
(2004)\end{array}$ & No & $\mathrm{E}$ & $2.6(42)$ \\
\hline $\begin{array}{c}\text { Biopollution } \\
\text { assessment scheme }\end{array}$ & Baltic Sea & $\begin{array}{l}\text { Aquatic } \\
\text { taxa }\end{array}$ & \begin{tabular}{|c|} 
Olenin et al. \\
$(2007)$
\end{tabular} & No & $\mathrm{E}$ & $16.2(211)$ \\
\hline $\begin{array}{l}\text { Conceptual framework } \\
\text { for prioritisation of } \\
\text { invasive alien species } \\
\text { for management } \\
\text { according to their } \\
\text { impact }\end{array}$ & Global & Generic & $\begin{array}{c}\text { Kumschick et } \\
\text { al. (2012) }\end{array}$ & Yes & E /SE & $14.1(113)$ \\
\hline $\begin{array}{c}\text { Generic ecological } \\
\text { impact assessments } \\
\text { of alien species in } \\
\text { Norway }\end{array}$ & Norway & Generic & \begin{tabular}{|c|} 
Sandvik et al. \\
(2013)
\end{tabular} & No & $\mathrm{E}$ & $5.9(41)$ \\
\hline $\begin{array}{c}\text { Review of impacts } \\
\text { of invasive alien } \\
\text { marine species on } \\
\text { ecosystem services and } \\
\text { biodiversity }\end{array}$ & Europe & Marine taxa & $\begin{array}{l}\text { Katsanevakis } \\
\text { et al. (2014) }\end{array}$ & Yes & $\mathrm{E} / \mathrm{SE}$ & $55.3(332)$ \\
\hline $\begin{array}{c}\text { EICAT } \\
\text { (Environmental } \\
\text { Impact Classification } \\
\text { for Alien Taxa) }\end{array}$ & Global & Generic & \begin{tabular}{|} 
Blackburn et \\
al. (2014), \\
Hawkins et \\
al. (2015)
\end{tabular} & No & $\mathrm{E}$ & $81.2(487)$ \\
\hline $\begin{array}{l}\text { GISS (Generic Impact } \\
\text { Scoring System) }\end{array}$ & Europe & Generic & $\begin{array}{l}\text { Nentwig et } \\
\text { al. (2016) }\end{array}$ & No & $\mathrm{E} / \mathrm{SE}$ & $16.8(67)$ \\
\hline $\begin{array}{c}\text { SEICAT (Socio- } \\
\text { Economic Impact } \\
\text { Classification of Alien } \\
\text { Taxa) }\end{array}$ & Global & Generic & $\begin{array}{c}\text { Bacher et al. } \\
(2018)\end{array}$ & No & SE & $39.5(79)$ \\
\hline $\begin{array}{l}\text { InSEAT (INvasive } \\
\text { Species Effects } \\
\text { Assessment Tool) }\end{array}$ & Global & Generic & $\begin{array}{c}\text { Martinez- } \\
\text { Cillero et al. } \\
(2019)\end{array}$ & Yes & $\mathrm{E} / \mathrm{SE}$ & $4(4)$ \\
\hline
\end{tabular}

alien species on other ecosystems or geographic areas. The INSEAT framework (INvasive Species Effects Assessment Tool) developed by Martinez-Cillero et al. (2019) adopts a bidirectional scoring system to quantify ecosystem service gains and losses caused by alien species. To date, the INSEAT scheme has been tested on 18 alien species in Great Britain (Martinez-Cillero et al. 2019). The renewed attention paid toward ecosystem services and disservices linked to alien species (Vaz et al. 2017; Vilà and Hulme 2017; Potgieter et al. 2019b; Shackleton et al. 2019a; Milanović et al. 2020) might promote the future application of the scheme across different regions and taxonomic groups.

Several frameworks focusing on deleterious impacts still explicitly recognise the existence of beneficial impacts caused by alien species (Bomford et al. 2008; Blackburn 
et al. 2014; Copp et al. 2016). For instance, the EFSA risk assessment framework developed by the European Food Safety Authority (2011) suggests identifying and describing any beneficial effect caused by aliens on the provisioning and regulation of ecosystem services but specifies that such impacts should not be scored. The absence of a scoring system for beneficial impacts was not only motivated by the intrinsic scope of risk assessment frameworks, which consider multiple factors, such as introduction pathways or establishment probability, to estimate whether an alien species can become deleterious (Leung et al. 2012; Kumschick et al. 2020b). The EFSA members also stressed that "assessing positive impacts is extremely difficult and may also be inappropriate or cause a potential conflict of interest for risk assessors if introductions are intentional". Both conceptual and methodological reasons could thus explain why frameworks assessing both beneficial and deleterious impacts are less frequently cited, and applied, than those assessing deleterious impacts only. The latter are used to a greater extent not only because they specifically help to prioritise alien species according to the magnitude of deleterious impacts, but also because unidirectional frameworks might have reached a higher level of acceptance, clarity and understanding over time. The relatively limited attention given to beneficial effects of alien species across impact assessment frameworks seems thus to reflect a general tendency in invasion science to consciously exclude beneficial impacts for various reasons rather than an attempt to deny their existence.

Below we review arguments for a greater consideration of positive and beneficial impacts caused by alien species. We collected the arguments from a set of 47 papers and illustrate each argument with examples. We grouped the arguments into two categories (value-free and value-laden) that reflect whether each argument has been formulated independently from, or in combination with, ethical and societal values. Arguments grouped in the value-free category consider negative and positive impacts as numerical decrease or increase of an attribute (e.g. the concentration of soil nutrients; Jeschke et al. 2014). Positive and negative impacts do not denote human values (Kumschick et al. 2012), but rather quantify bi-directional changes caused by alien species "as neutrally as possible" (Jeschke et al. 2014). In accordance with this valuefree perspective, in our manuscript we strictly define positive impacts as quantitative increases in attributes of the recipient systems. Arguments grouped in the value-laden category, on the contrary, refer to how impacts are perceived according to ethical and societal values (Jeschke et al. 2014). Impacts are generally considered deleterious or beneficial if they damage or benefit attributes linked to ethical and societal values (human well-being). In accordance to this value-laden perspective, in our manuscript we strictly define beneficial impacts as bi-directional quantitative changes (i.e. including both increases and decreases) in attributes of the recipient systems that are associated with benefits based on human values. Therefore, although negative and positive impacts are often considered as deleterious and beneficial, respectively (examples 1, 3 and 4 in Fig. 1), under our definitions, some negative impacts can less intuitively be perceived as beneficial (example 2 in Fig. 1), and some positive impacts as deleterious (example 3 in Fig. 1). 


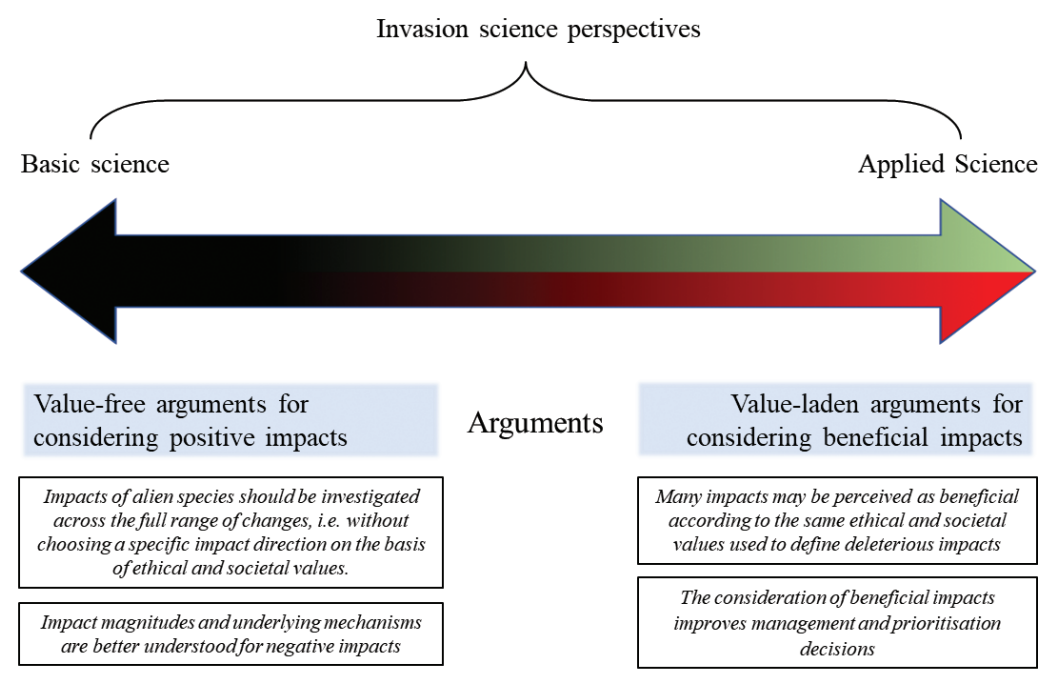

Positive and negative impacts indicate, respectively, how alien species increase and decrease a given attribute independently from ethical and societal values

\section{Examples of impacts}

Beneficial and deleterious impacts indicate how the impact of alien species is perceived according to specific ethical and societal values

$\begin{array}{ll}\text { The impact is considered negative } & \begin{array}{l}\text { The impact is perceived as } \\ \text { deleterious to nature conservation } \\ \text { The impact is perceived as } \\ \text { deleterious to eco-tourism }\end{array} \\ \text { The impact is considered negative } & \begin{array}{l}\text { The impact is perceived as } \\ \text { deleterious to nature conservation }\end{array} \\ \text { The impact is perceived as } \\ \text { beneficial to livestock farmers }\end{array}$

Figure I. Schematic representation of the gradient of perspectives in invasion science. These perspectives i) contribute to the formulation of general arguments that invoke a greater consideration of positive and beneficial impacts; ii) help to distinguish between negative/positive impacts and deleterious/beneficial impacts. Four examples (1-4) are also provided to illustrate a conceptual distinction between positive/ negative impacts (black text) and beneficial/deleterious impacts (red and green text). 
We show how the development of impact assessment frameworks assessing positive and beneficial impacts can benefit the field of invasion science and we offer suggestions on how this development should be carried out.

\section{Collection and value-based classification of arguments}

We conducted a thorough, but non-exhaustive, literature review to identify arguments for considering positive and beneficial impacts of alien species. We started with papers on the topic that were already known to us and followed up on other papers that referred to them or were cited in them. Articles were selected only if they had broad aims, i.e. they were not restricted to a single case study or taxonomic group. The purpose of this review was to exemplify arguments why authors invoke greater consideration of positive and beneficial impacts in invasion science. However, we do not aim to make quantitative statements about the frequency of these arguments in the field.

In the papers selected, arguments stem from the different perspectives and interests of authors. Like in related disciplines, such as conservation biology (Scott et al. 2007), invasion scientists have disparate standpoints and interests that span from a basic science perspective to an applied science perspective (Humair et al. 2014; Estévez et al. 2015). The former perspective suggests that similarly to any other natural phenomenon, impacts of alien species should be investigated as neutrally as possible (Slobodkin 2001; Brown and Sax 2005). Therefore, the influence of ethical and societal values on the investigation of impacts needs to be minimised in order to adopt a value-free, scientific approach (Slobodkin 2001; Brown and Sax 2005; Sagoff 2018). At the other extreme, the applied science perspective recommends that invasion science "must serve and be relevant to communities" (Munro et al. 2019). Thus, since invasion science concerns, among others, "costs and benefits of the presence and abundance of introduced organisms with reference to human value systems" (Richardson et al. 2007), a value-laden scientific approach could be adopted in the study of alien species. We are aware that a complete distinction between these two perspectives is a simplification of the broad spectrum of the existing views in invasion science (Fig.1) (Humair et al. 2014; Estévez et al. 2015; Bartz and Kowarik 2019). However, such a distinction is still useful here for illustrating the key arguments (Fig. 1) that invoke a greater consideration of positive impacts (value-free arguments), and those which invoke a greater consideration of beneficial impacts (value-laden arguments).

\section{Value-free arguments for considering positive impacts}

Impacts of alien species should be investigated across the full range of changes, i.e. without choosing a specific impact direction on the basis of ethical and societal values.

All alien species will cause changes, i.e. impacts, to some attributes of their recipient systems (Ricciardi et al. 2013; Jeschke et al. 2014). These attributes may describe dif- 
ferent aspects of the recipient ecosystem, such as species diversity, total biomass, carbon sequestration capacity, fire intensity, pollination frequency, etc. Impacted attributes may also be associated with both human well-being and socio-economic aspects, such as the number of people employed in forestry or fishing, food security, livelihood and human connection to nature. Basic scientific arguments advocate that changes in attributes should be investigated independently from ethical values in order to be objective (Slobodkin 2001). Authors strictly supporting these arguments state that value judgements cannot be empirically tested and that some ecologists fallaciously confuse these judgements with descriptions of environmental changes (Brown and Sax 2005; Sagoff 2018). In other words, one should measure the increase of a given attribute (positive impact) and the decrease of the same attribute (negative impact) along the full spectrum of changes, without any specific focus on one of the two directions (Jeschke et al. 2014, Fig.1). Value-laden terms such as "beneficial" or "deleterious" should be avoided whereas terms such as "positive" or "negative" should be only used from a numerical standpoint, as in the increase or decrease in the value of a property (Brown and Sax 2005). Furthermore, this argument posits that invasion scientists should act similarly to astronomers or particle physicists, who analyse scientific phenomena without considering moral values or practical consequences of their scientific research (Slobodkin 2001; Brown and Sax 2004).

\section{Impact magnitudes and underlying mechanisms are better understood for nega- tive impacts}

Under a value-free perspective, value judgement should not interfere with the study of impacts; it is theoretically expected that studies targeting alien species assess their impacts on the recipient system independently and unbiasedly from impact directions (e.g. meta-analyses which use effect size, such as in Castro-Díez et al. 2019). However, biases towards negative impacts on native biota have been reported, i.e. predominantly reporting on native biota suffering from aliens and ignoring native biota that profit from the presence of alien species (Goodenough 2010; Schlaepfer et al. 2011; Fig.2). Furthermore, it is difficult to judge how large this alleged bias is because it is unknown if alien species more often cause a decrease (i.e. generate negative impacts), rather than an increase (i.e. generate positive impacts), to the attributes of their recipient systems (Charles and Dukes 2007; Vitule et al. 2012). An example of a negative impact may be the decrease of species diversity caused by alien populations of rodents introduced to islands (see also example 1, Fig.1), whereas an example of a positive impact may be the increase of local species diversity caused by the establishment of an alien invertebrate that acts as ecosystem engineer (Castilla et al. 2004).

Alternatively, there may be a bias toward studying and reporting negative impacts (Guerin et al. 2018). Multiple negative impacts of alien species (e.g. decrease in native population size) were considered as deleterious based on ethical and societal values (Jeschke et al. 2014; Bartz and Kowarik 2019). The urgency to investigate the conspicuous deleterious impacts that some aliens cause to native communities and human activities 


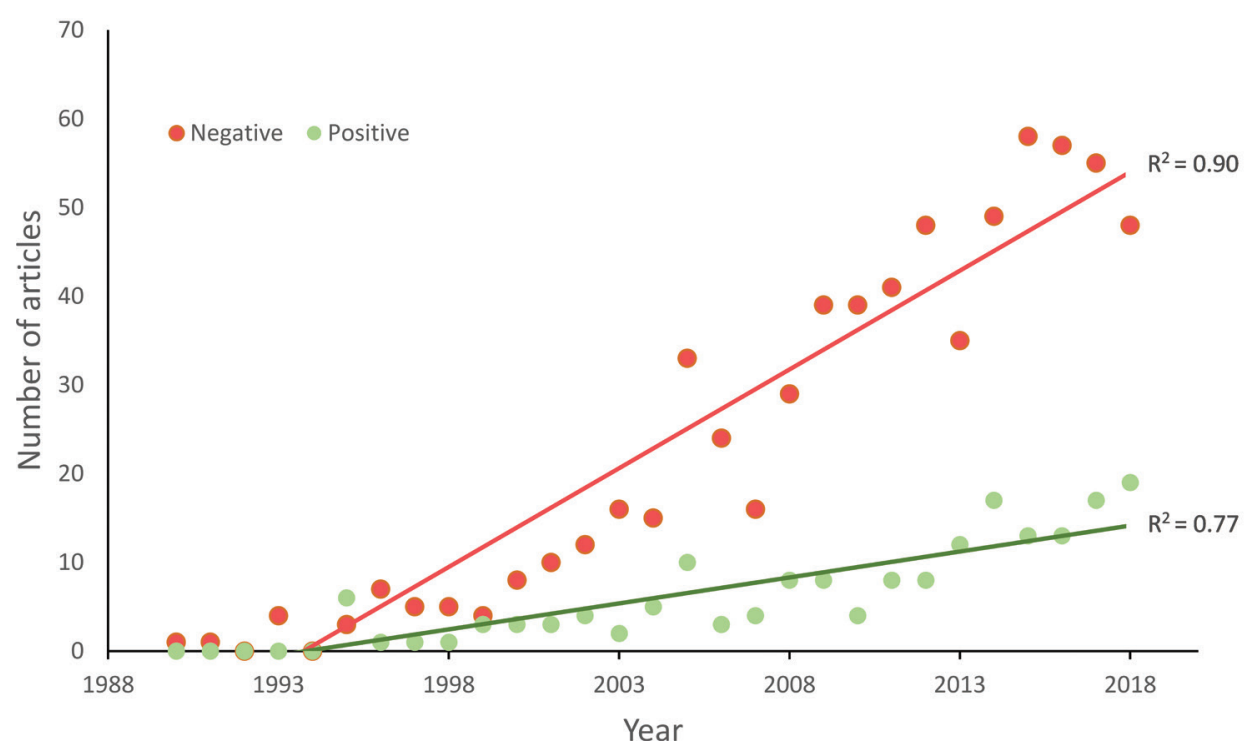

Figure 2. Plot reporting the number of articles and fitted linear regression obtained using the following search strings in Google Scholar at the end of October 2019: In red: "negative * of alien species "OR "negative* of non-native species " OR "negative* of exotic species" OR "costs of alien species " OR "costs of non-native species " OR "costs of exotic species"; In green: "positive* of alien species "OR "positive * of non-native species "OR "positive * of exotic species" OR "benefits of alien species "OR "benefits of non-native species "OR "benefits of exotic species".

(Richardson et al. 2000; Pyšek et al. 2008; Simberloff et al. 2012) might have contributed to this bias even among natural scientists. Such urgency was, for instance, emphasised during the Fourth Meeting of the Conference of the Parties to the Convention on Biological Diversity held in Slovakia in 1998, which first considered "including the subject of alien invasive species in its longer-term programme of work". The report of the meeting specifically noted "the significant adverse ecological and economic effects of certain alien species on biological diversity and human health" and "the importance of taking a precautionary and ecosystem approach when dealing with issues related to alien species" (UNEP 1998). The following editions of the conference considered "alien species that threaten ecosystems, habitat or species" as a cross-cutting and priority issue relevant to biological diversity, and advocated for the prevention and mitigation of their deleterious impacts, which has become a major cornerstone of invasion science. In addition to this, since many alien species were deliberately introduced to provide benefits to humans, such benefits might have seemed obvious, thereby preventing their systematic study. Many invasion scientists might also have investigated the unwanted deleterious consequences of alien taxa introductions in order to counterbalance a favourable attitude from many stakeholders towards alien taxa intentionally introduced for agriculture and forestry (Simberloff and Stiling 1996; Louda et al. 2003; Pyšek et al. 2008).

As most research assessing the impacts of alien species has been directed toward negative impacts, the magnitude of positive impacts has been rarely systematically 
assessed and quantified by using statistical or semi-quantitative tools (Goodenough 2010). Instead, the literature record of positive impacts seems rather anecdotal, with impacts usually defined according to human values (Vilà et al 2010; Schlaepfer et al. 2011). Thus, there are not only fewer studies that report positive impacts, but these studies often lack a systematic and evidence-based approach to classify and compare these impacts (Vilà et al 2010). Consequently, detailed descriptions of the mechanisms by which alien species can benefit their recipient ecological and the socio-economic systems are also scarce. Some mechanisms by which aliens positively affect the diversity and abundance of native taxa by providing food and refuge have been identified by Robinson et al. (2007), Goodenough (2010), Schlaepfer et al. (2011), McQuaid and Griffiths (2014) and Tassin and Kull (2015). Additionally, Kumschick et al. (2012) described mechanisms such as herbivory, competition or predation by which aliens may affect species that are degrading the ecosystem and thereby restore its historical functional state. Further studies on these underlying mechanisms may provide ecoevolutionary insights around alien-native coevolution, rapid adaptation, biotic resistance and niche vacancy. Greater knowledge has probably been gained around socioeconomic benefits to human-well-being, as multiple authors identified mechanisms by which aliens increase ecosystem services and decrease ecosystem disservices (Katsanevakis et al. 2014; Vaz et al. 2017; Knapp et al. 2019; Shackleton et al. 2019a; Milanović et al. 2020). Despite these efforts, unified systematic approaches to capture the diversity of positive and beneficial impacts of aliens across taxa and geographic regions are still lacking.

\section{Value-laden arguments for considering beneficial impacts}

\section{Many impacts may be perceived as beneficial according to the same ethical and societal values used to define deleterious impacts}

Although impacts cannot be defined as deleterious or beneficial in an absolute way, changes caused by alien species may still be perceived as deleterious or beneficial according to societal and ethical values (Fig.1, Vilà et al. 2010; Kumschick et al. 2012; Jeschke et al. 2014; Bartz and Kowarik 2019). Alien species can alter the demography of endangered populations and permanently modify native communities (Doherty et al. 2008, Gurevitch and Padilla 2004). Since native populations and communities have high conservation value, their decrease (i.e. negative impact) can be considered deleterious from a value-laden perspective (example 1, Fig. 1). This nature conservation perspective guided the development of some impact assessment frameworks frequently used (Vilà et al. 2019), such as the GISS framework (Nentwig et al. 2016) and the EICAT framework (Blackburn et al. 2014; Hawkins et al 2015; IUCN 2020), which both assess the deleterious impacts of alien species on native taxa. Alien species may also be perceived as deleterious to socio-economic systems and human well-being. For example, when alien species impede human activities such as fishing and farming or 
impair human health (Mazza et al. 2014; Rai and Singh 2020), personal safety or material and immaterial assets (Bacher et. al. 2018). Deleterious impacts on the social and economic sectors have been captured in the SEICAT framework (Socio-Economic Impact Classification of Alien Taxa), which adopts a scoring system analogous to EICAT to assess how human activities are affected by alien species (Bacher et al. 2018). Some impact assessment frameworks such as GISS (Nentwig et al. 2016) and INSEAT (Martinez-Cillero 2019), and many risk assessment frameworks, evaluate deleterious socio-economic impacts (for a review of impact assessment frameworks see Strubbe et al. 2019 and Vilà et al. 2019; for a review of risk assessment frameworks see Leung et al. 2012 and Kumschick and Richardson 2013).

Analogously to negative impacts that are perceived as deleterious to native communities and humans, many positive impacts can be considered beneficial according to values associated with nature conservation and human well-being. For example, some alien species may moderately increase fire frequency in their introduced range, thus providing benefits to native pyrophytes which require fire for germination (example 3 in Fig. 1). Alien plants can also increase the biomass of a recipient ecosystem, thus being beneficial to global carbon sequestration (example 4 in Fig. 1). Additionally, many alien species increase attributes that are relevant to societal values and human wellbeing. In other words, they increase existent, or provide additional, ecosystem services or beneficial contributions to people's quality of life (Díaz et al. 2018) such as food and water provision, soil and sand stabilisation and nitrogen fixation (Vaz et al. 2017; Milanović et al. 2019; Shackleton et al. 2019a). In a world of increasing environmental issues, aliens can also help to reduce the impact of other stressors. Examples include alien plants which mitigate the effects of climate change by facilitating coastal protection from erosion and favouring carbon sequestration (example 4 in Fig. 1, Essl. et al. 2017, in Castro-Díez et al. 2019). However, not all environmental and socio-economic beneficial impacts coincide with positive impacts; for example, in the impact scoring framework proposed by Kumschick et al. (2012), beneficial impacts of alien animals are quantified by measuring to what extent they reduce the population density of species degrading the ecosystem (e.g. pest species). In other words, a negative impact (e.g. decrease of pest species abundance), may thus be considered beneficial from a nature conservation standpoint or according to other values and interests (example 2, Fig.1). An alien bio-control agent (e.g. a parasitoid wasp) that reduces the abundance of an agricultural pest can be similarly considered beneficial to farmers and other stakeholders. Such species can thus provide additional benefits to humans by reducing ecosystem disservices (Vaz et al. 2017; Knapp et al. 2019; Milanović et al. 2019).

\section{The consideration of beneficial impacts improves management and prioritisa- tion decisions}

Human values and interests associated with the impacts of alien species affect whether and how these species can be managed. Some alien species have been intentionally 
introduced because of the benefits they can provide to people (Castro-Díez et al. 2019). Additionally, many aliens cause low or insignificant impacts to their recipient systems and can be simply considered inconsequential for ecosystems and society (Zengeya et al. 2017). Beneficial and inconsequential species do not generally require management interventions, and their prompt identification facilitates the allocation of management resources elsewhere (van Wilgen and Richardson 2004; Zengeya et al. 2017). Aliens that provide beneficial impacts to human well-being might, however, decrease the demography of native populations, thus being deleterious from a nature conservation standpoint (Doherty et al. 2008). More generally, stakeholders may have such disparate values and interests that their perception toward alien species can be simultaneously favourable and unfavourable (Novoa et al. 2018; Shackleton et al 2019b). Such disparate values (examples 2,3 and 4, Fig.1) may cause a conflict of interests among different stakeholders and hamper management implementation (Jeschke et al. 2014; Crowley et al. 2017; Essl et al. 2017; Zengeya et al. 2017). For instance, van Wilgen and Wilson (2018) showed that control and regulation of a few alien taxa such as pine trees (Pinus spp.) and the rainbow trout (Oncorhynchus mykiss) were extremely controversial in South Africa, given these species cause both beneficial and deleterious impacts on different sectors of society. Analogously, the control of Paterson's curse (Echium plantagineum), an alien plant that is highly toxic to livestock, has generated conflicts between Australian farmers and beekeepers, with the latter benefiting from the nectar produced by the plant (Messing 2000). Transparent and evidence-based descriptions of beneficial and deleterious impacts of alien species may thus help to support prioritisation, clarify and motivate values underlying management, identify conflicts of interests and advance dialogue among stakeholders.

\section{Reasons and suggestions to develop frameworks assessing positive and benefi- cial impacts}

We show that arguments from different perspectives invoke a greater consideration of positive and beneficial impacts in invasion science. The development of assessment frameworks that classify deleterious and negative impacts through a standardised and evidence-based approach (e.g. EICAT and SEICAT) has improved our understanding of such impacts. These frameworks describe the different ways in which alien taxa deleteriously interact with native taxa (impact mechanisms), and quantify the severity of such interactions (impact magnitude) (Blackburn et al. 2014; Nentwig et al. 2016; Bacher et al. 2018). The application of these frameworks to different taxa and ecosystems has allowed for the investigation of factors driving impact magnitude (e.g., Kumschick et al. 2013; Measey et al. 2016; Novoa et al. 2016; Evans et al. 2018) and the ranking of hundreds of alien species based on their deleterious impacts (e.g. Kumschick et al. 2015; Nentwig et al. 2018). Given the above considerations, some of these frameworks might be adapted to assess beneficial impacts. Detailed descriptions 
provided by these frameworks around mechanisms by which alien species cause deleterious impacts can be extended to capture mechanisms linked to beneficial impacts (i.e. Blackburn et al. 2014; Nentwig et al. 2016). Approaches adopted by existing frameworks to evaluate assessment uncertainty can also be followed because they might help to overcome methodological limitations associated with transparency, clarity and reproducibility (Vilà et al. 2019; Probert et al. 2020). However, some conceptual and methodological aspects should be considered when developing frameworks that assess positive and beneficial impacts.

Impact assessment frameworks classify deleterious impacts according to their magnitudes, i.e. by measuring to what extent alien taxa affect reference attributes. This facilitates comparison among taxonomically distant alien species and across spatial scale and habitats. However, several different strategies have been adopted to measure impact magnitudes. Frameworks such as those proposed by Sandvik et al. (2013) and MartinezCillero et al. (2019) use ranking scales which distinguish between low (or noticeable), substantial (or medium), and high (intense) impacts. The scales may be associated with parameters that can be numerically quantified such as the spatial extent of the non-native range, genetic diversity, fitness and abundance of native individuals or provision of ecosystem services (Bartz and Kowarik 2019; Crystal-Ornelas and Lockwood 2020). As a consequence, such scoring scales could be easily adapted to assess bidirectional changes (Martinez-Cillero et al. 2019). Although general scaling approaches may allow the assessment of many alien species and adopt a fully symmetrical bidirectional approach (Zengeya et al. 2017), they may still be prone to subjectivity, especially when the distinction between the magnitude levels is not accurately described. The EICAT framework (Blackburn et al. 2014), on the contrary, clarifies differences between magnitude levels by assuming that with each level of impact magnitude (from minimal concern to massive), a different level of organisation is affected (from native individuals to native communities). Clarity in describing distinct levels of impact magnitude might have contributed to the increasing use of EICAT among scientists and practitioners (Kumschick et al. 2020a). An analogous scoring approach that assesses ecological impacts based on organisation level has been also developed by Olenin et al. (2007). Such approaches, however, define the highest levels of impact magnitude according to the capacity of alien species to cause the extinction of a native species (Olenin et al. 2007; Blackburn et al. 2014). As extinction cannot be exactly mirrored by any other positive ecological phenomenon, the development of a perfectly symmetrical bidirectional adaptation of these schemes might be difficult to achieve. As a consequence, not all impact assessment frameworks can, or need to, adopt a fully symmetric bidirectional scoring scale to assess impact magnitudes. This limitation should be recognised in any conceptual attempt to adapt existing frameworks in order to assess the benefits of alien species.

Impact assessment frameworks are generally developed based on different values that should be recognised and explicitly stated. Values and perspectives influence how we select the attributes of ecosystems or human activities that will be assessed (Bartz and Kowarik 2019; Strubbe et al. 2019) and must be considered when making management recommendations and in final decision making (Probert et al. 2020). However, values 
and perspectives also define the aims and the intrinsic limitations of each framework. For example, when evaluating the changes caused by an alien species to the community of the recipient environment, we should choose and specify which taxa are taken into consideration. Scientists embracing a conservation standpoint might consider only native, or even endangered taxa, as they aim to quantify alien impacts on species of conservation interest. Scientists who follow a more basic science approach, however, could consider all taxa independently of their origin, as their aim is to measure the negative or positive impacts of aliens from a value-free perspective. The development of a framework that assesses deleterious and beneficial impacts should thus disclose which values underlie the framework and whether the framework distinguishes between deleterious/beneficial impacts and negative/positive impacts. Such a disclosure of values can also be facilitated by the development, and adoption, of a more neutral and transparent terminology in invasion science. The distinction we have drawn in our manuscript between positive/ negative and beneficial/deleterious impacts, for example, has been instrumental in defining impacts regardless of whether they were associated with human values. Both terms "positive" and "negative", however, have in general an intrinsic value connotation and are often used as synonyms of "beneficial" or "favourable" and "detrimental" or "deleterious" in invasion science and other scientific disciplines. Given this lack of linguistic consistency, there might be the necessity to develop a more neutral and transparent terminology in invasion science that unequivocally clarifies whether an impact is defined in accordance to human values or only from a mathematical and value-free perspective.

\section{Conclusion}

When underlying values are explicitly stated and intrinsic limitations are openly recognised, the development of frameworks that assess positive and beneficial impacts might advance our scientific understanding of impact dynamics and generate reliable information for management and prioritisation. Adapting existing or developing novel frameworks to quantify these impacts should not be seen as an attempt to outweigh or discount deleterious impacts of alien taxa (EFSA 2011) but rather as an opportunity to provide an additional piece of information for scientists, managers and policymakers.

\section{Acknowledgments}

This paper emerged from a workshop on 'Frameworks used in Invasion Science' hosted by the DSI-NRF Centre of Excellence for Invasion Biology in Stellenbosch, South Africa, 11-13 November 2019, that was supported by the National Research Foundation of South Africa and Stellenbosch University. We thank the handling editor and reviewers for their helpful comments and suggestions, which improved the quality of the manuscript. We thank Ingolf Kühn, Belinda Gallardo, Ross Shackleton and Louisa Wood for fruitful discussions around the evaluation of positive and beneficial impacts of alien spe- 
cies through impact assessment frameworks. GV, LV, AFP and SB acknowledge funding from the Swiss National Science Foundation (grant numbers 31003A_179491 and 31BD30_184114) and the Belmont Forum - BiodivERsA International joint call project InvasiBES (PCI2018-092939). SK acknowledges the support of the DSI-NRF Centre of Excellence for Invasion Biology (CIB) and Stellenbosch University, and the South African Department of Forestry, Fisheries and the Environment (DFFtE) noting that this publication does not necessarily represent the views or opinions of DFFtE or its employees.

\section{References}

Bacher S, Blackburn TM, Essl F, Genovesi P, Heikkilä J, Jeschke JM, Jones G, Keller R, Kenis M, Kueffer C, Martinou AF, Nentwig W, Pergl J, Pyšek P, Rabitsch W, Richardson DM, Roy HE, Saul WC, Scalera R, Vilà M, Wilson JRU, Kumschick S (2018) Socio-economic impact classification of alien taxa (SEICAT). Methods in Ecology and Evolution 9: 159168. https://doi.org/10.1111/2041-210X.12844

Bartz R, Kowarik I (2019) Assessing the environmental impacts of invasive alien plants: A review of assessment approaches. NeoBiota 43: 69-99. https://doi.org/10.3897/neobiota.43.30122

Blackburn TM, Essl F, Evans T, Hulme PE, Jeschke JM, Kühn I, Kumschick S, Marková Z, Mrugała A, Nentwig W, Pergl J, Pyšek P, Rabitsch W, Ricciardi A, Richardson DM, Sendek A, Vilà M, Wilson JRU, Winter M, Genovesi P, Bacher S (2014) A Unified Classification of Alien Species Based on the Magnitude of their Environmental Impacts. PLoS Biology 12. https://doi.org/10.1371/journal.pbio. 1001850

Boltovskoy D, Sylvester F, Paolucci EM (2018) Invasive species denialism: Sorting out facts, beliefs, and definitions. Ecology and Evolution 8: 11190-11198. https://doi.org/10.1002/ece3.4588

Bomford M, Glover J (2004) Risk assessment model for the import and keeping of exotic freshwater and estuarine finfish A report produced by the Bureau of Rural Sciences for The Department of Environment and Heritage. http://www.dcita.gov.au/cca [March 31, 2020] Brown JH, Sax DF (2005) Biological invasions and scientific objectivity: Reply to Cassey et al. (2005). Austral Ecology 30: 481-483. https://doi.org/10.1111/j.1442-9993.2005.01504.x

Castilla JC, Lagos NA, Cerda M (2004) Marine ecosystem engineering by the alien ascidian Pyura praeputialis on a mid-intertidal rocky shore. Marine Ecology Progress Series 268: 119-130. https://doi.org/10.3354/meps268119

Castro-Díez P, Vaz AS, Silva JS, van Loo M, Alonso Á, Aponte C, Bayón Á, Bellingham PJ, Chiuffo MC, DiManno N, Julian K, Kandert S, La Porta N, Marchante H, Maule HG, Mayfield MM, Metcalfe D, Monteverdi MC, Núńez MA, Ostertag R, Parker IM, Peltzer DA, Potgieter LJ, Raymundo M, Rayome D, Reisman-Berman O, Richardson DM, Roos RE, Saldańa A, Shackleton RT, Torres A, Trudgen M, Urban J, Vicente JR, Vilà M, Ylioja T, Zenni RD, Godoy O (2019) Global effects of non-native tree species on multiple ecosystem services. Biological Reviews 94: 1477-1501. https://doi.org/10.1111/brv.12511

Charles H, Dukes JS (2007) Impacts of invasive species on ecosystem services. Biological Invasions 193: 217-237. https://doi.org/10.1007/978-3-540-36920-2_13 
Copp GH, Russell IC, Peeler EJ, Gherardi F, Tricarico E, Macleod A, Cowx IG, Nunn AD, Occhipinti-Ambrogi A, Savini D, Mumford J, Britton JR (2016) European Non-native Species in Aquaculture Risk Analysis Scheme - a summary of assessment protocols and decision support tools for use of alien species in aquaculture. Fisheries Management and Ecology 23: 1-11. https://doi.org/10.1111/fme.12074

Crowley SL, Hinchliffe S, McDonald RA (2017) Invasive species management will benefit from social impact assessment. Journal of Applied Ecology 54: 351-357. https://doi. org/10.1111/1365-2664.12817

Crystal-Ornelas R, Lockwood JL (2020) The "known unknowns" of invasive species impact measurement. Biological Invasions 22: 1513-1525. https://doi.org/10.1007/s10530-020-02200-0

Díaz S, Pascual U, Stenseke M, Martín-López B, Watson RT, Molnár Z, Hill R, Chan KMA, Baste IA, Brauman KA, Polasky S, Church A, Lonsdale M, Larigauderie A, Leadley PW, van Oudenhoven APE, van der Plaat F, Schröter M, Lavorel S, Aumeeruddy-Thomas Y, Bukvareva E, Davies K, Demissew S, Erpul G, Failler P, Guerra CA, Hewitt CL, Keune H, Lindley S, Shirayama Y (2018) Assessing nature's contributions to people. Science 359: 270-272. https://doi.org/10.1126/science.aap8826

Doherty TS, Glen AS, Nimmo DG, Ritchie EG, Dickman CR (2016) Invasive predators and global biodiversity loss. Proceedings of the National Academy of Sciences of the United States of America 113: 11261-11265. https://doi.org/10.1073/pnas.1602480113

EFSA Panel on Plant Health (2011) Guidance on the environmental risk assessment of plant pests. EFSA Journal 9: 1-121. https://doi.org/10.2903/j.efsa.2011.2460

Essl F, Hulme PE, Jeschke JM, Keller R, Pyšek P, Richardson DM, Saul WC, Bacher S, Dullinger S, Estévez RA, Kueffer C, Roy HE, Seebens H, Rabitsch W (2017) Scientific and normative foundations for the valuation of alien-species impacts: Thirteen core principles. BioScience 67: 166-178. https://doi.org/10.1093/biosci/biw160

Essl F, Dullinger S, Rabitsch W, Hulme PE, Hülber K, Jarošík V, Kleinbauer I, Krausmann F, Kühn I, Nentwig W, Vilà M, Genovesi P, Gherardi F, Desprez-Loustau ML, Roques A, Pyšek P (2011) Socioeconomic legacy yields an invasion debt. Proceedings of the National Academy of Sciences of the United States of America 108: 203-207. https://doi. org/10.1073/pnas.1011728108

Estévez RA, Anderson CB, Pizarro JC, Burgman MA (2015) Clarifying values, risk perceptions, and attitudes to resolve or avoid social conflicts in invasive species management. Conservation Biology 29: 19-30. https://doi.org/10.1111/cobi.12359

Evans T, Kumschick S, Şekercioğlu ÇH, Blackburn TM (2018) Identifying the factors that determine the severity and type of alien bird impacts. Diversity and Distributions 24: 800-810. https://doi.org/10.1111/ddi.12721

Goodenough A (2010) Are the ecological impacts of alien species misrepresented? A review of the "native good, alien bad" philosophy. Community Ecology 11: 13-21. https://doi. org/10.1556/ComEc.11.2010.1.3

Guerin GR, Martín-Forés I, Sparrow B, Lowe AJ (2018) The biodiversity impacts of nonnative species should not be extrapolated from biased single-species studies. Biodiversity and Conservation 27: 785-790. https://doi.org/10.1007/s10531-017-1439-0

Gurevitch J, Padilla DK (2004) Are invasive species a major cause of extinctions? Trends in Ecology and Evolution 19: 470-474. https://doi.org/10.1016/j.tree.2004.07.005 
Hawkins CL, Bacher S, Essl F, Hulme PE, Jeschke JM, Kühn I, Kumschick S, Nentwig W, Pergl J, Pyšek P, Rabitsch W, Richardson DM, Vilà M, Wilson JRU, Genovesi P, Blackburn TM (2015) Framework and guidelines for implementing the proposed IUCN Environmental Impact Classification for Alien Taxa (EICAT). Diversity and Distributions 21: 1360-1363. https://doi.org/10.1111/ddi.12379

Humair F, Edwards PJ, Siegrist M, Kueffer C (2014) Understanding misunderstandings in invasion science: why experts don't agree on common concepts and risk assessments. NeoBiota 20: 1-30. https://doi.org/10.3897/neobiota.20.6043

IUCN (2020) IUCN EICAT Categories and Criteria. The Environmental Impact Classification for Alien Taxa (EICAT): First edition. Gland, Switzerland and Cambridge, UK: IUCN. https://doi.org/10.2305/IUCN.CH.2020.05.en

Jeschke JM, Bacher S, Blackburn TM, Dick JTA, Essl F, Evans T, Gaertner M, Hulme PE, Kühn I, Mrugała A, Pergl J, Pyšek P, Rabitsch W, Ricciardi A, Richardson DM, Sendek A, Vilà M, Winter M, Kumschick S (2014) Defining the impact of non-native species. Conservation Biology 28: 1188-1194. https://doi.org/10.1111/cobi.12299

Katsanevakis S, Wallentinus I, Zenetos A, Leppäkoski E, Çinar ME, Oztürk B, Grabowski M, Golani D, Cardoso AC (2014) Impacts of invasive alien marine species on ecosystem services and biodiversity: A pan-European review. Aquatic Invasions 9: 391-423. https://doi.org/10.3391/ai.2014.9.4.01

Knapp S, Winter M, Zehnsdorf A, Kühn I (2019) How Good Are Bad Species? Atlas of Ecosystem Services. https://doi.org/10.1007/978-3-319-96229-0_34

Kuebbing SE, Nuñez MA (2018) Current understanding of invasive species impacts cannot be ignored: potential publication biases do not invalidate findings. Biodiversity and Conservation 27: 1545-1548. https://doi.org/10.1007/s10531-018-1527-9

Kumar Rai P, Singh JS (2020) Invasive alien plant species: Their impact on environment, ecosystem services and human health. Ecological Indicators 111: 106020. https://doi. org/10.1016/j.ecolind.2019.106020

Kumschick S, Richardson DM (2013) Species-based risk assessments for biological invasions: Advances and challenges. Diversity and Distributions 19: 1095-1105. https://doi. org/10.1111/ddi.12110

Kumschick S, Bacher S, Blackburn TM (2013) What determines the impact of alien birds and mammals in Europe? Biological Invasions 15: 785-797. https://doi.org/10.1007/s10530012-0326-6

Kumschick S, Bacher S, Dawson W, Heikkilä J, Sendek A, Pluess T, Robinson T, Kühn I (2012) A conceptual framework for prioritization of invasive alien species for management according to their impact. NeoBiota 15: 69-100. https://doi.org/10.3897/neobiota.15.3323

Kumschick S, Bacher S, Evans T, Marková Z, Pergl J, Pyšek P, Vaes-Petignat S, van der Veer G, Vilà M, Nentwig W (2015) Comparing impacts of alien plants and animals in Europe using a standard scoring system. Journal of Applied Ecology 52: 552-561. https://doi. org/10.1111/1365-2664.12427

Kumschick S, Bacher S, Bertolino S, Blackburn TM, Evans T, Roy HE, Smith K (2020) Appropriate uses of EICAT protocol, data and classifications. In: Wilson JR, Bacher S, Daehler CC, Groom QJ, Kumschick S, Lockwood JL, Robinson TB, Zengeya TA, Richardson DM (Eds) Frameworks used in Invasion Science. NeoBiota 62: 193-212. https://doi. org/10.3897/neobiota.62.51574 
Kumschick S, Wilson JRU, Foxcroft LC (2020) A framework to support alien species regulation: the Risk Analysis for Alien Taxa (RAAT). NeoBiota 62: 213-239. https://doi. org/10.3897/neobiota.62.51031

Leung B, Roura-Pascual N, Bacher S, Heikkilä J, Brotons L, Burgman MA, Dehnen-Schmutz K, Essl F, Hulme PE, Richardson DM, Sol D, Vilà M (2012) TEASIng apart alien species risk assessments: A framework for best practices. Ecology Letters 15: 1475-1493. https:// doi.org/10.1111/ele.12003

Louda SM, Pemberton RW, Johnson MT, Follett PA (2003) Nontarget effects - The achille's heel of biological control? Retrospective analyses to reduce risk associated with biocontrol introductions. Annual Review of Entomology 48: 365-396. https://doi.org/10.1146/annurev.ento.48.060402.102800

Martinez-Cillero R, Willcock S, Perez-Diaz A, Joslin E, Vergeer P, Peh KSH (2019) A practical tool for assessing ecosystem services enhancement and degradation associated with invasive alien species. Ecology and Evolution 9: 3918-3936. https://doi.org/10.1002/ ece3.5020

Mazza G, Tricarico E, Genovesi P, Gherardi F (2014) Biological invaders are threats to human health: An overview. Ethology Ecology and Evolution 26: 112-129. https://doi.org/10.10 80/03949370.2013.863225

McGeoch MA, Genovesi P, Bellingham PJ, Costello MJ, McGrannachan C, Sheppard A (2016) Prioritizing species, pathways, and sites to achieve conservation targets for biological invasion. Biological Invasions 18: 299-314. https://doi.org/10.1007/s10530-015-1013-1

McQuaid KA, Griffiths CL (2014) Alien reef-building polychaete drives long-term changes in invertebrate biomass and diversity in a small, urban estuary. Estuarine, Coastal and Shelf Science 138: 101-106. https://doi.org/10.1016/j.ecss.2013.12.016

Measey GJ, Vimercati G, de Villiers FA, Mokhatla M, Davies SJ, Thorp CJ, Rebelo AD, Kumschick S (2016) A global assessment of alien amphibian impacts in a formal framework. Diversity and Distributions 22: 970-981. https://doi.org/10.1111/ddi.12462

Messing RH (2000) The Impact of Nontarget Concerns on the Practice of Biological Control. Nontarget Effects of Biological Control. Springer, US, 45-55. https://doi.org/10.1007/9781-4615-4577-4_4

Milanović M, Knapp S, Pyšek P, Kühn I (2020) Linking traits of invasive plants with ecosystem services and disservices. Ecosystem Services 42: 101072. https://doi.org/10.1016/j. ecoser.2020.101072

Morse LE, Randall JM, Benton N, Hiebert R, Lu S (2004) An invasive species assessment protocol: evaluating non-native plants for their impact on biodiversity. Version 1. 42 pp.

Munro D, Steer J, Linklater W (2019) On allegations of invasive species denialism. Conservation Biology 33: 797-802. https://doi.org/10.1111/cobi.13278

Nentwig W, Bacher S, Kumschick S, Pyšek P, Vilà M (2018) More than "100 worst” alien species in Europe. Biological Invasions 20: 1611-1621. https://doi.org/10.1007/s10530-017-1651-6

Nentwig W, Bacher S, Pyšek P, Vilà M, Kumschick S (2016) The generic impact scoring system (GISS): a standardized tool to quantify the impacts of alien species. Environmental Monitoring and Assessment 188. https://doi.org/10.1007/s10661-016-5321-4

Novoa A, Kumschick S, Richardson DM, Rouget M, Wilson JRU (2016) Native range size and growth form in Cactaceae predict invasiveness and impact. NeoBiota 30: 75-90. https:// doi.org/10.3897/neobiota.30.7253 
Novoa A, Shackleton R, Canavan S, Cybèle C, Davies SJ, Dehnen-Schmutz K, Fried J, Gaertner M, Geerts S, Griffiths CL, Kaplan H, Kumschick S, Le Maitre DC, Measey GJ, Nunes AL, Richardson DM, Robinson TB, Touza J, Wilson JRU (2018) A framework for engaging stakeholders on the management of alien species. Journal of Environmental Management 205: 286-297. https://doi.org/10.1016/j.jenvman.2017.09.059

Olenin S, Minchin D, Daunys D (2007) Assessment of biopollution in aquatic ecosystems. Marine Pollution Bulletin 55: 379-394. https://doi.org/10.1016/j.marpolbul.2007.01.010

Oreska MPJ, Aldridge DC (2011) Estimating the economic costs of invasive alien species as a tool for prioritization. CAB Reviews: Perspectives in Agriculture, Veterinary Science, Nutrition and Natural Resources 6. https://doi.org/10.1079/PAVSNNR20116049

Pimentel D, McNair S, Janecka J, Wightman J, Simmonds C, O’Connell C, Wong E, Russel L, Zern J, Aquino T, Tsomondo T (2001) Economic and environmental threats of alien plant, animal, and microbe invasions. Agriculture, Ecosystems and Environment 84: 1-20. https://doi.org/10.1016/S0167-8809(00)00178-X

Potgieter LJ, Gaertner M, O'Farrell PJ, Richardson DM (2019a) A fine-scale assessment of the ecosystem service-disservice dichotomy in the context of urban ecosystems affected by alien plant invasions. Forest Ecosystems 6: 1-16. https://doi.org/10.1186/s40663-019-0200-4

Potgieter LJ, Gaertner M, O'Farrell PJ, Richardson DM (2019b) Perceptions of impact: Invasive alien plants in the urban environment. Journal of Environmental Management 229: 76-87. https://doi.org/10.1016/j.jenvman.2018.05.080

Probert AF, Volery L, Kumschick S, Vimercati G, Bacher S (2020) Understanding uncertainty in the Impact Classification for Alien Taxa (ICAT) assessments. In: Wilson JR, Bacher S, Daehler CC, Groom QJ, Kumschick S, Lockwood JL, Robinson TB, Zengeya TA, Richardson DM (Eds) Frameworks used in Invasion Science. NeoBiota 62: 387-405. https:// doi.org/10.3897/neobiota.62.52010

Probert AF, Ward DF, Beggs JR, Lin S-L, Stanley MC (2020) Conceptual Risk Framework: Integrating Ecological Risk of Introduced Species with Recipient Ecosystems. BioScience 70: 71-79. https://doi.org/10.1093/biosci/biz131

Pyšek P, Richardson DM, Pergl J, Jarošík V, Sixtová Z, Weber E (2008) Geographical and taxonomic biases in invasion ecology. Trends in Ecology and Evolution 23: 237-244. https:// doi.org/10.1016/j.tree.2008.02.002

Ricciardi A, Hoopes MF, Marchetti MP, Lockwood JL (2013) Progress toward understanding the ecological impacts of nonnative species. Ecological Monographs 83: 263-282. https:// doi.org/10.1890/13-0183.1

Richardson DM, Pyšek P (2008) Fifty years of invasion ecology - the legacy of Charles Elton. Diversity and Distributions 14: 161-168. https://doi.org/10.1111/j.14724642.2007.00464.x

Richardson DM, Pyšek P, Rejmánek M, Barbour MG, Dane Panetta F, West CJ (2000) Naturalization and invasion of alien plants: Concepts and definitions. Diversity and Distributions 6: 93-107. https://doi.org/10.1046/j.1472-4642.2000.00083.x

Robinson TB, Branch GM, Griffiths CL, Govender A, Hockey PAR (2007) Changes in South African rocky intertidal invertebrate community structure associated with the invasion of the mussel Mytilus galloprovincialis. Marine Ecology Progress Series 340: 163-171. https:// doi.org/10.3354/meps340163 
Roy HE, Rabitsch W, Scalera R, Stewart A, Gallardo B, Genovesi P, Essl F, Adriaens T, Bacher S, Booy O, Branquart E, Brunel S, Copp GH, Dean H, D’hondt B, Josefsson M, Kenis M, Kettunen M, Linnamagi M, Lucy F, Martinou A, Moore N, Nentwig W, Nieto A, Pergl J, Peyton J, Roques A, Schindler S, Schönrogge K, Solarz W, Stebbing PD, Trichkova T, Vanderhoeven S, van Valkenburg J, Zenetos A (2018) Developing a framework of minimum standards for the risk assessment of alien species. Journal of Applied Ecology 55: 526-538. https://doi.org/10.1111/1365-2664.13025

Sagoff M (2018) What Is Invasion Biology? Ecological Economics 154: 22-30. https://doi. org/10.1016/j.ecolecon.2018.07.023

Sandvik H, Sæther BE, Holmern T, Tufto J, Engen S, Roy HE (2013) Generic ecological impact assessments of alien species in Norway: A semi-quantitative set of criteria. Biodiversity and Conservation 22: 37-62. https://doi.org/10.1007/s10531-012-0394-z

Schlaepfer MA, Sax DF, Olden JD (2011) The potential conservation value of non-native species. Conservation Biology 25: 428-437. https://doi.org/10.1111/j.1523-1739.2010.01646.x

Scott JM, Rachlow JL, Lackey RT, Pidgorna AB, Aycrigg JL, Feldman GR, Svancara LK, Rupp DA, Stanish DI, Steinhorst RK (2007) Policy advocacy in science: Prevalence, perspectives, and implications for conservation biologists. Conservation Biology 21: 29-35. https://doi. org/10.1111/j.1523-1739.2006.00641.x

Seebens H, Blackburn TM, Dyer EE, Genovesi P, Hulme PE, Jeschke JM, Pagad S, Pyšek P, Winter M, Arianoutsou M, Bacher S, Blasius B, Brundu G, Capinha C, Celesti-Grapow L, Dawson W, Dullinger S, Fuentes N, Jäger H, Kartesz J, Kenis M, Kreft H, Kühn I, Lenzner B, Liebhold A, Mosena A, Moser D, Nishino M, Pearman D, Pergl J, Rabitsch W, RojasSandoval J, Roques A, Rorke S, Rossinelli S, Roy HE, Scalera R, Schindler S, Štajerová K, Tokarska-Guzik B, Van Kleunen M, Walker K, Weigelt P, Yamanaka T, Essl F (2017) No saturation in the accumulation of alien species worldwide. Nature Communications 8: 1-9. https://doi.org/10.1038/ncomms 14435

Shackleton RT, Shackleton CM, Kull CA (2019a) The role of invasive alien species in shaping local livelihoods and human well-being: A review. Journal of Environmental Management 229: 145-157. https://doi.org/10.1016/j.jenvman.2018.05.007

Shackleton RT, Richardson DM, Shackleton CM, Bennett B, Crowley SL, Dehnen-Schmutz K, Estévez RA, Fischer A, Kueffer C, Kull CA, Marchante E, Novoa A, Potgieter LJ, Vaas J, Vaz AS, Larson BMH (2019b) Explaining people's perceptions of invasive alien species: A conceptual framework. Journal of Environmental Management 229: 10-26. https://doi. org/10.1016/j.jenvman.2018.04.045

Simberloff D, Stiling P (1996) How risky is biological control? Ecology 77: 1965-1974. https:// doi.org/10.2307/2265693

Simberloff D, Souza L, Nũnez MA, Barrios-Garcia MN, Bunn W (2012) The natives are restless, but not often and mostly when disturbed. Ecology 93: 598-607. https://doi. org/10.1890/11-1232.1

Slobodkin LB (2001) The good, the bad and the reified. Evolutionary Ecology Research 3: 1-13.

Srebaliene G, Olenin S, Minchin D, Narščius A (2019) A comparison of impact and risk assessment methods based on the IMO Guidelines and EU invasive alien species risk assessment frameworks. PeerJ 2019. https://doi.org/10.7717/peerj.6965 
Strubbe D, White R, Edelaar P, Rahbek C, Shwartz A (2019) Advancing impact assessments of non-native species: Strategies for strengthening the evidence-base. NeoBiota 51: 41-64. https://doi.org/10.3897/neobiota.51.35940

Tassin J, Kull CA (2015) Facing the broader dimensions of biological invasions. Land Use Policy 42: 165-169. https://doi.org/10.1016/j.landusepol.2014.07.014

UNEP (1998) Report of the Fourth Meeting of the Conference of the Parties to the Convention on Biological Diversity. In: Conference of the Parties to the Convention on Biological Diversity, Fourth meeting. UNEP/CBD/COP/4/27, Bratislava, Slovakia.

Vaz AS, Kueffer C, Kull CA, Richardson DM, Vicente JR, Kühn I, Schröter M, Hauck J, Bonn A, Honrado JP (2017) Integrating ecosystem services and disservices: insights from plant invasions. Ecosystem Services 23: 94-107. https://doi.org/10.1016/j.ecoser.2016.11.017

Vilà M, Basnou C, Pyšek P, Josefsson M, Genovesi P, Gollasch S, Nentwig W, Olenin S, Roques A, Roy D, Hulme PE, Andriopoulos P, Arianoutsou M, Bazos I, Kokkoris I, Yannitsaros A, Zikos A, Augustin S, Cochard PO, Lopez-Vaamonde C, Sauvard D, Yart A, Bacher S, Bretagnolle F, Gasquez J, Chiron F, Kark S, Shirley S, Clergeau P, Cocquempot C, Coeur d'Acier A, Dorkeld F, Migeon A, Navajas M, David M, Delipetrou P, Georghiou K, Desprez-Loustau ML, Didziulis V, Essl F, Galil BS, Hejda M, Jarosik V, Pergl J, Perglová I, Kühn I, Winter M, Kühn PW, Marcer A, Pino J, McLoughlin M, Minchin D, Panov VE, Pascal M, Poboljsaj K, Scalera R, Sedlácek O, Zagatti P (2010) How well do we understand the impacts of alien species on ecosystem services? A pan-European, cross-taxa assessment. Frontiers in Ecology and the Environment 8: 135-144. https://doi.org/10.1890/080083

Vilà M, Hulme PE (2017) Non-native Species, Ecosystem Services, and Human Well-Being. In: Impact of Biological Invasions on Ecosystem Services. Springer International Publishing, 1-14. https://doi.org/10.1007/978-3-319-45121-3_1

Vilà M, Gallardo B, Preda C, García-Berthou E, Essl F, Kenis M, Roy HE, González-Moreno P (2019) A review of impact assessment protocols of non-native plants. Biological Invasions 21: 709-723. https://doi.org/10.1007/s10530-018-1872-3

Vitule JRS, Freire CA, Vazquez DP, Nuñez MA, Simberloff D (2012) Revisiting the Potential Conservation Value of Non-Native Species. Conservation Biology 26: 1153-1155. https:// doi.org/10.1111/j.1523-1739.2012.01950.x

van Wilgen BW, Richardson DM (2014) Challenges and trade-offs in the management of invasive alien trees. Biological Invasions 16: 721-734. https://doi.org/10.1007/s10530013-0615-8

van Wilgen BW, Wilson JR (2018) The status of biological invasions and their management in South Africa in 2017. South African National Biodiversity Institute, Kirstenbosch and DST-NRF Centre of Excellence for Invasion Biology, Stellenbosch. https://doi. org/10.13140/RG.2.2.31003.52002

Zengeya T, Ivey P, Woodford DJ, Weyl O, Novoa A, Shackleton R, Richardson D, van Wilgen B (2017) Managing conflict-generating invasive species in South Africa: Challenges and trade-offs. Bothalia 47: 1-11. https://doi.org/10.4102/abc.v47i2.2160 